\title{
ACCELERATION OF CRACK GROWTH UNDER INTERMITTENT OVERSTRESSING IN DIFFERENT ENVIRONMENTS
}

\author{
RYOICHI KOTERAZAWA $\dagger$ and TAKAYOSHI NOSHO $†$ \\ Institute of Engineering Mechanics, University of Tsukuba, Tsukuba, Japan
}

(Received in final form I March 1991)

\begin{abstract}
Fatigue crack growth behaviour under intermittent overstressing was investigated in moist air, dry air, nitrogen and vacuum with low carbon steels under tension-compression loading with a few tests under compression-tension loading. A very small number of cycles of overstress applied intermittently during a very large number of cycles of understress below threshold caused significant acceleration, of about one hundred times, in crack growth rate as compared to the case of steady cyclic stress in the cases of moist air, dry air and nitrogen. In the region of low understress, the acceleration in moist air was appreciably less than that in dry air and nitrogen due to oxide-induced crack closure. The acceleration in vacuum was smaller than that in other environments over all understress levels, possibly because of rewelding. There was no effect of an overstress sequence on the acceleration.
\end{abstract}

\section{NOMENCLATURE}

$a=$ semi crack length

$a_{0}=$ semi notch length

$\mathrm{d} a / \mathrm{d} N=$ crack growth rate

$P=$ load

$\delta=$ displacement over the gauge length of specimen

$E=$ Young's modulus

$W, B=$ width and thickness of specimen

$K, \Delta K=$ stress intensity, stress intensity range

$K_{\mathrm{op}}=$ crack opening stress intensity

$\Delta K_{\mathrm{th}}=$ threshold stress intensity range

$\Delta K_{1}=$ stress intensity range for understress

$\Delta K_{2}=$ stress intensity range for overstress

$\Delta K_{\text {eff }}=$ effective stress intensity range

$\Delta K_{\text {leff }}=$ effective stress intensity range for understress

$\left(\Delta K_{\text {eff }}\right)_{\mathrm{th}}=$ threshold for effective stress intensity range

$n_{1}=$ number of cycles in an understress block of an intermittent overstress test

$n_{2}=$ number of cycles in an overstress block of an intermittent overstress test

$R_{\mathrm{ac}}=$ acceleration ratio for crack growth by intermittent overstressing $=\Delta a / 2(\mathrm{~d} a / \mathrm{d} N)_{\Delta K_{2}}$

$\Delta a=$ crack growth during one block of intermittent overstressing

$(\mathrm{d} a / \mathrm{d} N)_{\Delta K_{2}}=$ crack growth rate under steady cycling of $\Delta K_{2}$

$S_{\text {ox }}=$ oxide thickness measured by Auger spectroscopy

$S_{\mathrm{ox}}^{*}=$ oxide thickness estimated from crack closure data

\section{INTRODUCTION}

Fatigue strength of machine and structural components in service is sometimes considerably lower than the strength obtained by laboratory fatigue tests. One of the reasons for this discrepancy lies

†Author to whom all correspondence should be addressed.

†Present address: Department of Mechanical Engineering, Okayama University, Okayama, Japan. 
in the fact that most of the cyclic stresses applied to the components in service are below the fatigue limit, i.e. "understress" with very few cycles of overstress being applied intermittently. The Miner's linear cumulative damage law is far from valid in such cases.

One of the authors along with his colleagues [1-3] has conducted experimental studies on this problem with particular regard to the crack growth stage of the fatigue process and obtained results which show that a significant acceleration in crack growth rates (more than one hundred times) occurs in those cases where a very small number of cycles (e.g. 2 cycles) of overstress are applied intermittently between very large numbers of cycles (or the order of $10^{6}$ cycles) of understress, i.e. below the threshold stress intensity $\Delta K_{\mathrm{th}}$. These results indicate that $\Delta K_{\mathrm{th}}$, which has been thought to be an important design criterion in fracture mechanics, loses its physical meaning as the threshold for fatigue crack growth under variable stress conditions and the acceleration can be a vital factor that has to be considered in the design of components. Most of the work on fatigue crack growth under variable stresses, however, has been focused on the retardation of crack growth by overstressing [4] and more research is desired to study the acceleration aspects.

The crack growth acceleration tests cited above [1-3] were mostly made with circumferentially cracked round bar specimens using rotary bending fatigue machines and accurate values of stress intensity could not be obtained. The first objective of this study was therefore to carry out more sophisticated tests with centre notched plate specimens loaded in tension-compression (including compression-tension in a few tests) by a micro-computer controlled servohydraulic fatigue machine.

Effect of environment, on the other hand, is known to be important in fatigue crack growth behaviour and a number of studies are being carried out on this problem [5-9]. However, no work has been conducted concerning the effect of environment on the acceleration of crack growth by the process of intermittent overstressing as mentioned above. The second objective in this present study was to shed some light on this point by conducting crack growth acceleration tests in different environments together with crack closure and Auger spectroscopy analyses. Some tests were made also on the effect of sequence of overstressing (i.e, tension-compression type and compression-tension type overstress tests) which is known to be an important factor in retardation behaviour of crack growth after overstressing.

\section{TEST PROCEDURE}

Test materials used in this programme were two low carbon steels with almost the same properties (normalized at $920^{\circ} \mathrm{C}$ for $1 \mathrm{~h}$; tensile strength 449 and $433 \mathrm{MPa}$, yield point 305 and $327 \mathrm{MPa}$, elongation 34.5 and $40.0 \%$ for materials $\mathrm{A}$ and $\mathrm{B}$, respectively). They were machined into centre notched plate specimens (width 60 and $45 \mathrm{~mm}$, length of parallel section 160 and $50 \mathrm{~mm}$, thickness 7.5 and $5.5 \mathrm{~mm}$, notch length $2 a_{0} \cong 15$ and $11 \mathrm{~mm}$ for materials A and B, respectively) and tested by micro-computer controlled servohydraulic fatigue machines of basically the same type made by the same manufacturer, maximum load being $\mathrm{A}: \pm 98 \mathrm{kN}, \mathrm{B}: \pm 49 \mathrm{kN}$; machine $\mathrm{B}$ being furnished with a vacuum chamber. It is confirmed by fatigue crack growth tests in dry air under steady cyclic stresses and under intermittent overstresses that the two machines and the two low carbon steels yield virtually the same crack growth rate behaviour.

Tests were conducted in moist air, dry air, nitrogen and vacuum. Machine A and material A were used for the tests in moist air, dry air and nitrogen. Humidity of moist air and dry air was maintained at near constant values, i.e. $70-80$ and 20-30\%, respectively, in a chamber with a small amount of water and silica gel. For nitrogen tests, $0.3-0.51 / \mathrm{min}$ of nitrogen gas flowed through the chamber. Material $\mathrm{B}$ and machine $\mathrm{B}$ with a vacuum chamber at a pressure of about $7 \times 10^{-4} \mathrm{~Pa}$ 
were used for some tests. Oxide thicknesses on fracture surfaces were measured by means of sputtering in an Auger spectroscope because the effect of an oxide film on crack closure is known to be very important for fatigue crack growth [10].

Crack length was measured by a travelling microscope $(\times 20)$. Displacement $\delta$ over the gauge length $(12.5 \mathrm{~mm})$ of specimens was monitored by a clip gauge placed on the centre line of the specimen across the centre notch and it was recorded on an $X-Y$ recorder in the form of load-displacement hysteresis loops. Crack opening load was determined from the hysteresis loop according to the standard method after Elber [11]. Measurements of the hysteresis loop were made at intervals during crack growth; about 10-20 times for each test. The stress intensity factor was calculated by following equation,

$$
K=(P / B W) \sqrt{\pi a \sec (\pi a / W)} .
$$

\section{EXPERIMENTAL RESULTS AND DISCUSSION}

(A) Effects of environment on crack growth under nearly steady alternating stresses (stepped-load shedding tests)

Crack growth tests under nearly steady alternating stresses (stepped-load shedding tests after ASTM Standard E647-78T, stress ratio $R=K_{\min } / K_{\max }=-1$ ) were conducted in different environments in order to obtain basic data for the study of crack growth under intermittent overstressing. The test frequency was $20 \mathrm{~Hz}$. The crack growth rate data so obtained are shown in Fig. 1 as a

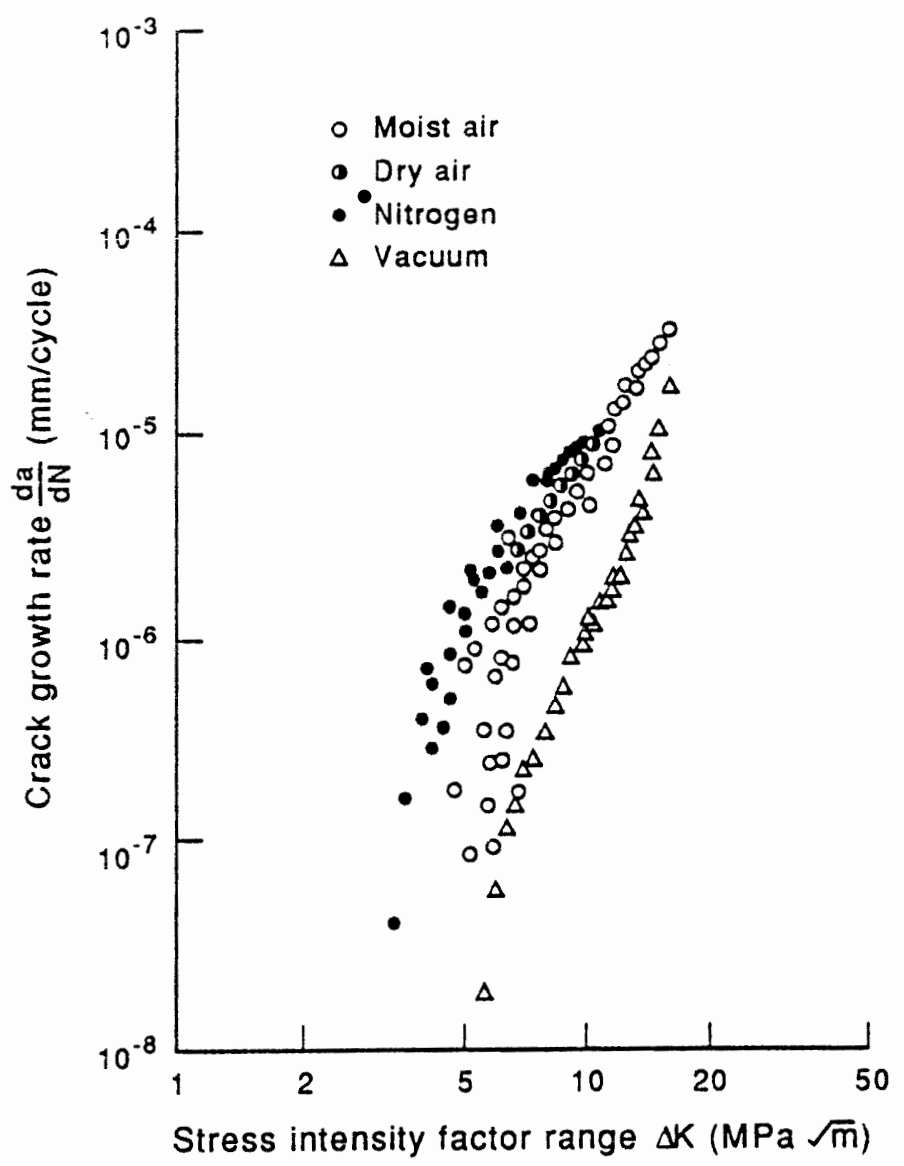

Fig. 1. Crack growth rate in stepped-load shedding tests as a function of stress intensity range. 


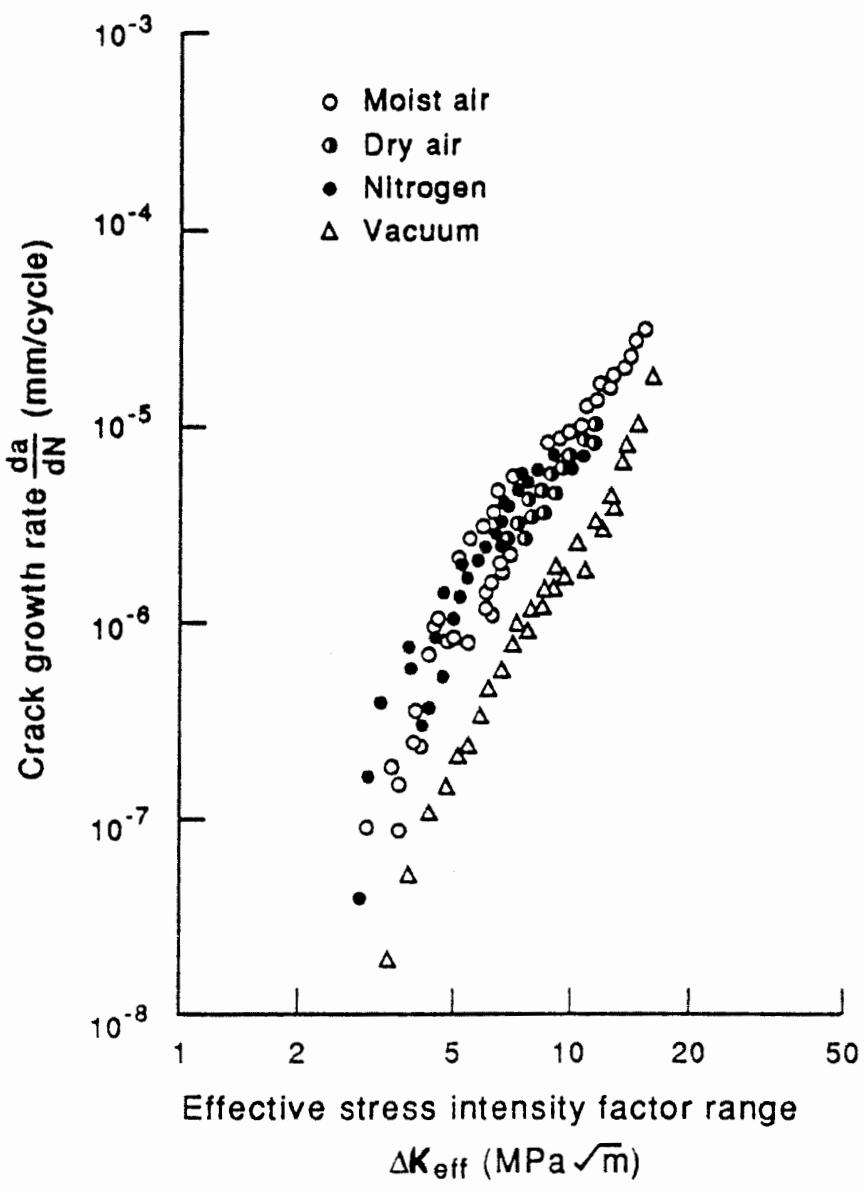

Fig. 2. Crack growth rate in stepped-load shedding tests as a function of effective stress intensity range.

function of stress intensity range $\Delta K$. Figure 2 shows $\mathrm{d} a / \mathrm{d} N$ as a function of effective stress intensity range $\Delta K_{\text {eff }}$ obtained from the measured crack opening load $\left(=\Delta K-K_{\text {op }}\right.$ ).

(i) Crack growth in moist air, dry air and nitrogen. Crack growth rates in different environments, shown in Fig. 1, agree with each other in the region of high crack growth rate. In the region of low growth rate, however, the rate in moist air is somewhat lower than in nitrogen. No data were obtained for dry air at the lower growth rates so no comparison can be made here. Accordingly, the threshold stress intensity, $\Delta K_{\text {th }}$, in moist air is higher than that in nitrogen. In the $\Delta K_{\text {eff }}$ diagram of Fig. 2, on the other hand, all of the data points, excluding vacuum data, lie around a smaller scatter band, suggesting that the difference of growth rates in the $\Delta K$ diagram is partially due to different crack closure behaviour.

(ii) Crack growth in vacuum. The crack growth rate in vacuum is appreciably lower than those in other environments over all regions of growth rate shown in the $\Delta K$ diagram. The difference is not eliminated in the $\Delta K_{\text {eff }}$ diagram. There must be some cause other than closure for the difference in this case which will be discussed later.

\section{(B) Effects of environment on crack growth under intermittent overstressing}

(i) Crack growth acceleration in different environments. Tests were conducted in moist air, dry air, nitrogen and vacuum under two level intermittent stressing illustrated in Fig. 3(a) where a very small number of cycles ( 2 cycles) of overstress $\Delta K_{2}$ of the tension-compression type are applied intermittently between very large numbers of cycles $\left(2 \times 10^{5}\right.$ cycles $)$ of understress, i.e. with $\Delta K_{1}$ below the threshold stress intensity $\Delta K_{\mathrm{th}}$. A value of $\Delta K_{2}$ is selected so that a steady application 

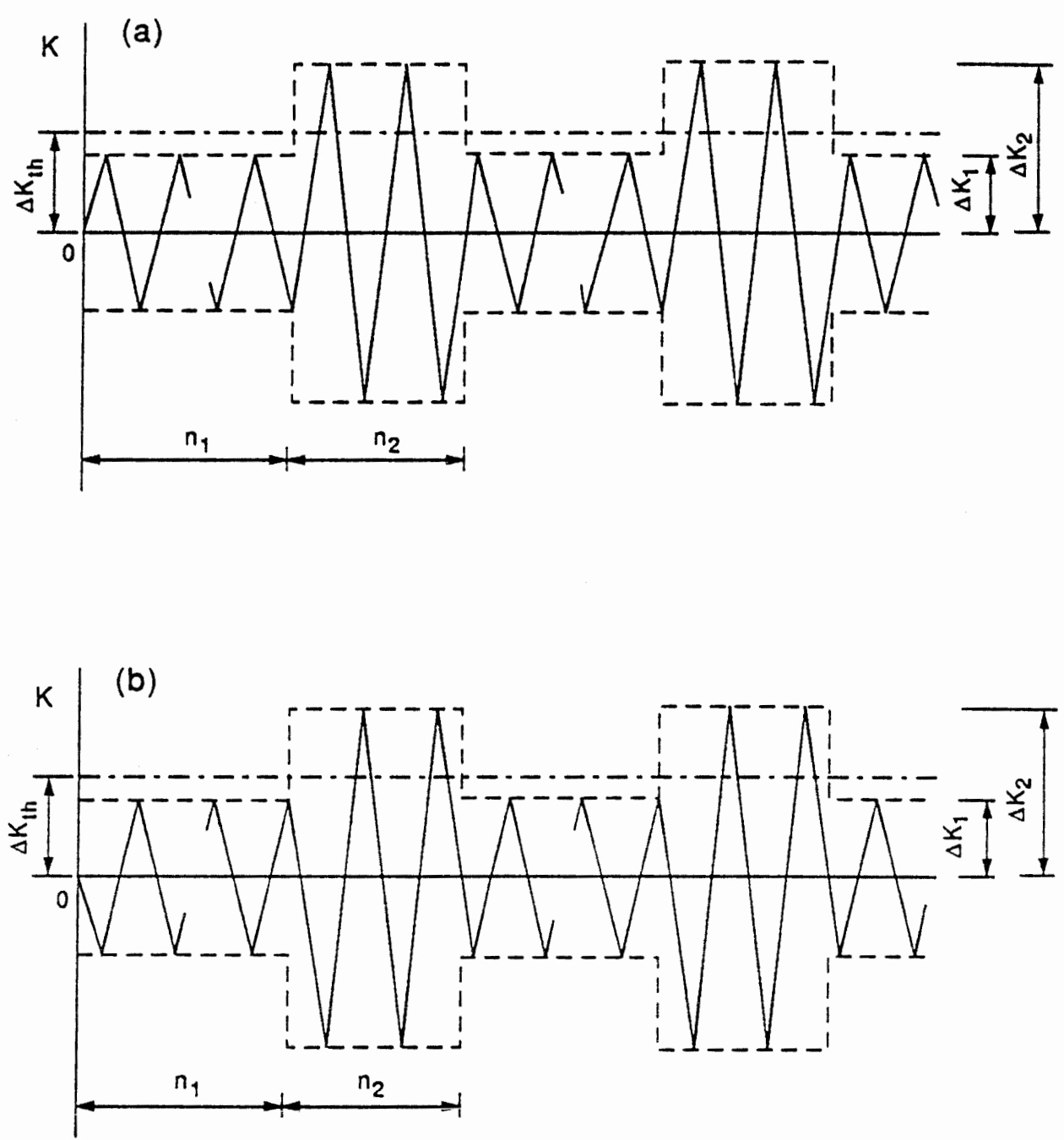

Fig. 3. Loading programs. (a) Tension-compression overloading and (b) compression-tension overloading.

at this level gives a crack growth rate of the order of $3 \times 10^{-5} \mathrm{~mm} / \mathrm{cycle}$. Frequencies of the overstress and the understress are 5 and $20 \mathrm{~Hz}$, respectively. The results are shown in Fig. 4 (designated as tension-compression loading) as an acceleration ratio $R_{\mathrm{ac}}$ versus $\Delta K_{1} / \Delta K_{\mathrm{th}}$ diagram, where $R_{\mathrm{ac}}$ is defined as actual crack growth during one program block of the intermittent overstressing, $\Delta a$, divided by a fictitious one, equal to $2(\mathrm{~d} a / \mathrm{d} N)_{\Delta K_{2}}$ which is obtained under the assumption that crack growth in any cycle during an intermittent overstress test is equal to that in one cycle during steady cycling at the same stress. (Note that $\mathrm{d} a / \mathrm{d} N$ during understressing is zero because an understress is below the threshold.)

The $R_{\mathrm{ac}}$ values for tests in dry air and nitrogen are close to those for the rotating bending and in-plane alternating bending (tension-compression type) tests which were conducted previously with similar materials in laboratory air [1-3], amounting to about 100 in the region of large values of the understress ratio. This confirms the finding on the acceleration factors in previous tests.

The acceleration is believed to be caused by the recovery of dislocation structures due to a large number of understress cycles [2]. That is, dislocation structures in the form of radial bands in a direction oblique to that of crack growth are observed around the crack tip after overstressing. The radial bands are transformed into dislocation free, large cell structures after a large amount of understress cycling. The radial band structure formed by overstressing provides a preferred crack 


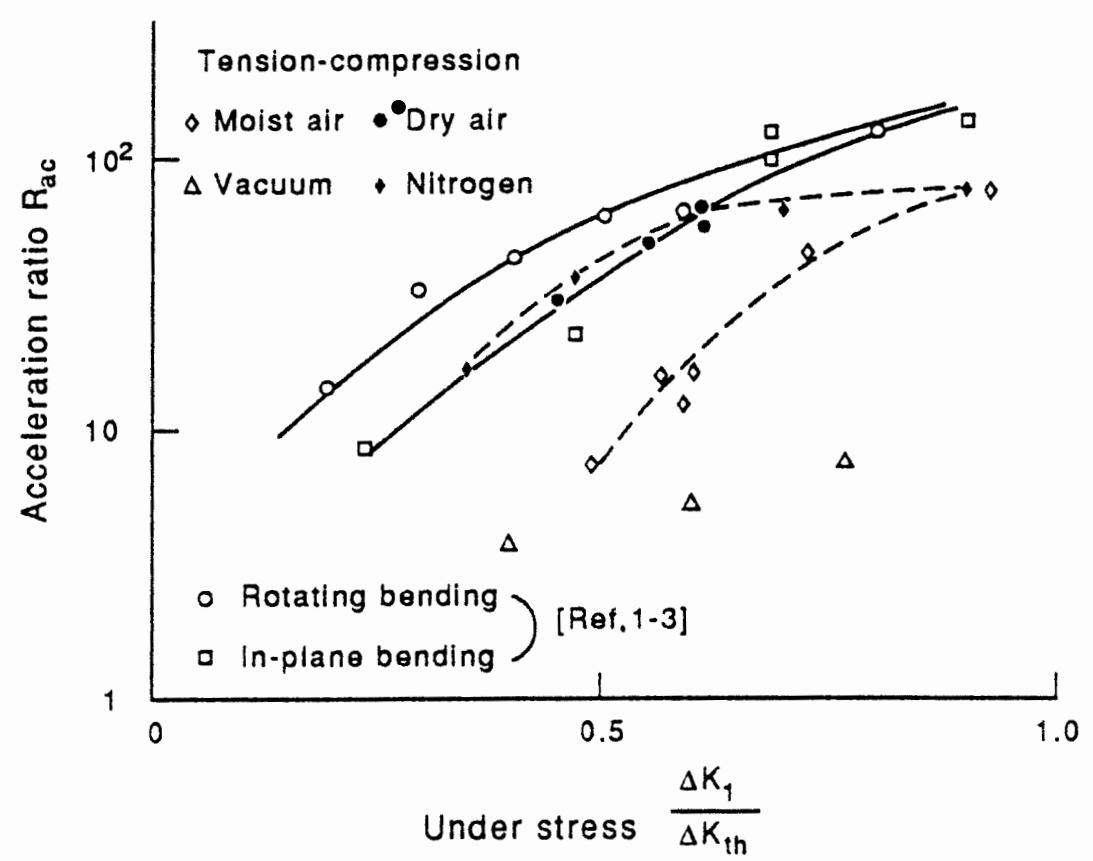

Fig. 4. Acceleration ratio $R_{\mathrm{ac}}$ for intermittent overstresses as a function of normalized understress $\Delta K_{1} / \Delta K_{\text {th }}$.

growth route which is followed during understressing, resulting in zig-zag crack growth which is observed on fracture surfaces as beach marks of a saw-tooth profile [1-3]. The well recovered structure, which results from understressing, enables crack growth and formation of the band structure to take place more easily on overstressing. These two mutually dependent factors are thought to be responsible for the acceleration.

In the case of moist air tests, the $R_{\mathrm{ac}}$ values in the region of high understress ratio are about the same as those in dry air and nitrogen, but they are appreciably smaller than those in other environments in the region of low understress ratio.

Acceleration in vacuum, on the other hand, is less than that in other environments over the whole region of understress. The difference is greater in the region of high understress ratio with the $R_{\mathrm{xc}}$ values in vacuum being about $1 / 5 \sim 1 / 10$ of those in other environments.

The reason for the environmental effects described above will be discussed in the following sections.

(C) Crack closure and acceleration of crack growth

Some role of crack closure was found in the effect of environment on crack growth in Fig. 2 for the case of stepped-load shedding tests. A similar effect may be expected in the case of intermittent overstressing and some measurements of crack closure during intermittent overstress tests were carried out. The measured crack opening levels $K_{\text {op }}$ are shown in Fig. 5 as a function of number of program blocks of intermittent overstresses. Measurements were made at the start of the intermittent overstress tests and during them, immediately before and just after overstressing. It should be noted here that the crack opening level after overstressing is nearly equal to that before overstressing. It is well known that the crack opening level rises after a tensile overstress due to residual compressive stresses developed by the tensile overstress within the plastic zone ahead of the crack tip [11]. The results shown here suggest that the residual stress is relieved by the compressive overstress applied immediately after the tensile overstressing [12, 13]. 


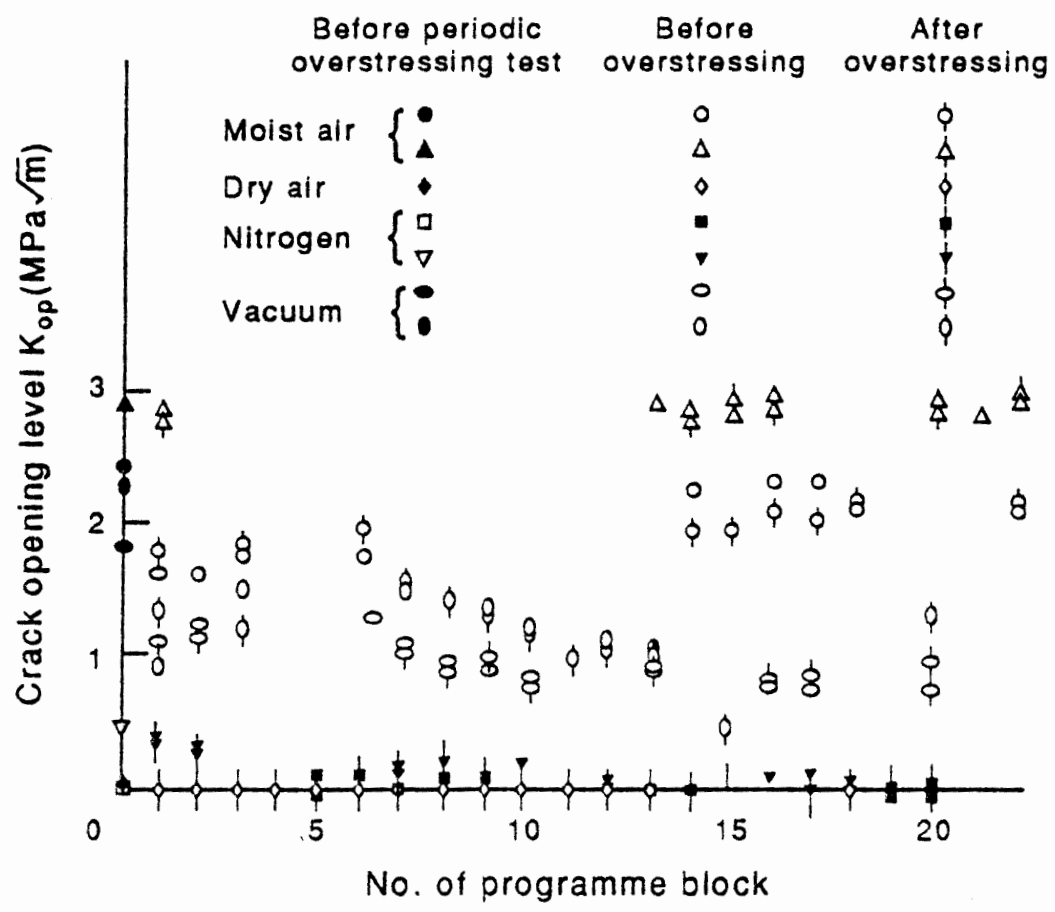

Fig. 5. Variation of crack opening level during intermittent overload tests.

The crack opening levels shown in Fig. 5 are low compared to the overstress peak so that the effective value of the overstress is not much different from the nominal value. However, it may have a large effect on the effective value of the understress which has a much smaller inominal value. Looking into the effect of environments, the opening levels in moist air tests are appreciably higher than those in other environments and this may explain the difference in the acceleration in these environments. To examine this point, the effective stress intensities for an understress $\Delta K_{\text {leff }}\left(=K_{1 \max }-K_{\mathrm{op}}\right)$ were calculated by using the closure data (average opening levels du armittent overstress tests). The $R_{\mathrm{ac}}$ values are shown as a function of $\Delta K_{\text {leff }} /\left(\Delta K_{\text {eff }}\right)_{\text {th }}$ $\left[\Delta K_{\text {leff }}\right.$ normalized by effective thresholds stress intensity $\left.\left(\Delta K_{\text {eff }}\right)_{\text {th }}\right]$ in Fig. 6. (For the case of a vacuum test, average opening levels during a steady period following about 10 programme blocks, were used for the calculation.) Data points for moist air lie along the same line as those for dry air and nitrogen, suggesting that the smaller $R_{\text {ac }}$ values in moist air shown in Fig. 4 were due to higher opening levels in this case. Data points for vacuum tests do not agree with those for other environments also in the $\Delta K_{\text {teff }}$ diagram (Fig. 6) and the small value of $R_{\mathrm{ac}}$ in this case cannot be attributed to crack closure. This will be discussed further in the next section.

\section{D) Fractographic analysis}

Examples of fractography are shown in Fig. 7 for fractures in different environments during intermittent overstressing. We can see, in Fig. 7(a) and (b) for dry air and nitrogen, fatigue fracture surfaces with beach marks created by intermittent overstressing (each line corresponds to a block of overstress) similar to those observed in previous studies [1-3]. In Fig. 7(c) for moist air, on the other hand, beach marks are hardly recognized, being covered by an oxide film. This is related to higher closure levels in moist air as stated above. On the fracture surface of the vacuum test [Fig. 7(d)] edges of ridges and valleys are not as sharp as those in Fig. 7(a) and (b) and beach marks are not observed. This might be a result of rewelding of fracture surfaces in 


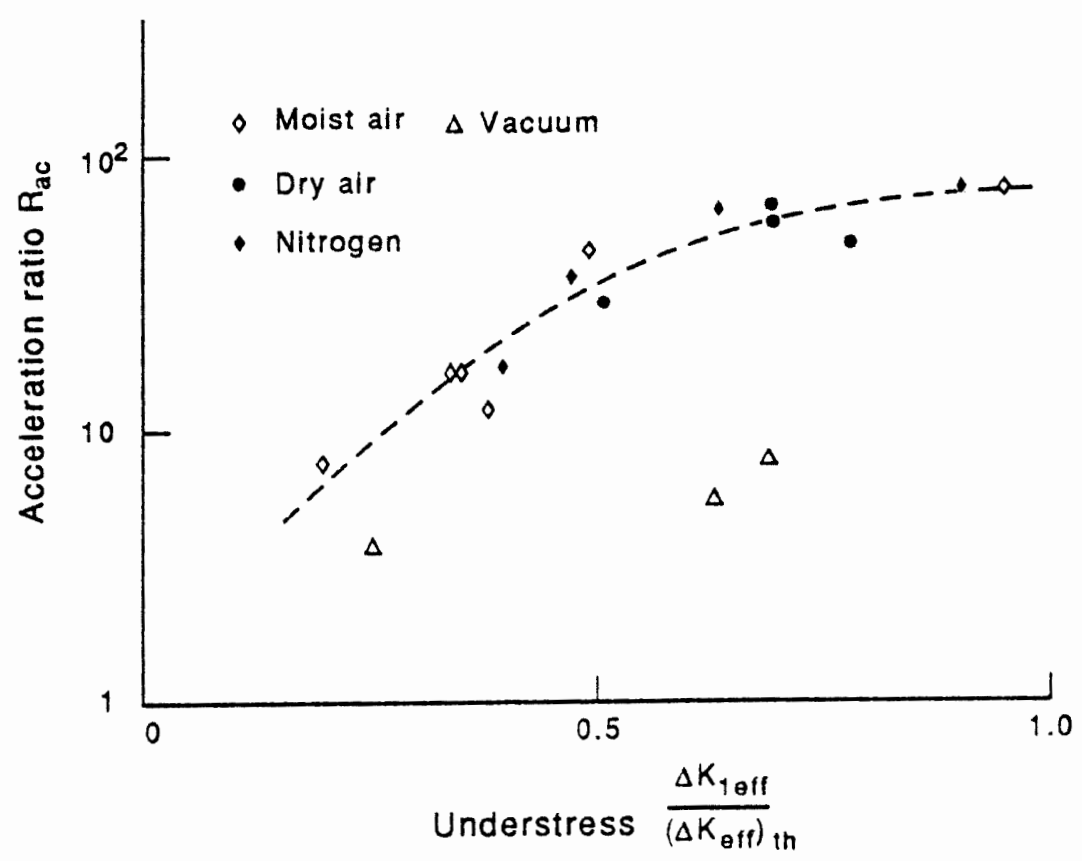

Fig. 6. Acceleration ratio $R_{\mathrm{ac}}$ for intermittent overstresses as a function of effective normalized understress $\Delta K_{\text {leff }} /\left(\Delta K_{\text {eff }}\right)_{\mathrm{th}}$.

vacuum $[8,9]$ and related to the low crack growth rate and acceleration in the vacuum environment as described above.

To look a little more into the effect of oxidation on the crack growth acceleration, the thickness of the oxide film on the fracture surfaces were measured by means of sputtering in an Auger spectroscope and an analysis of oxide induced crack closure was carried out, similar to that done in Ref. [10]. The results are shown in Table 1. Values of oxide thickness $S_{\text {ox }}^{*}$ estimated from closure levels by assuming that all of the closure is induced by oxidation, agree fairly well with measured values of $S_{\text {ox }}$, confirming the oxide induced closure as the cause of low crack growth acceleration in moist air.

Crack growth and acceleration behaviour in nitrogen was different from that in vacuum and similar to that in dry air. It might be questioned why an inert nitrogen environment did not cause similar behaviour to that in a vacuum environment. This is most probably because the nitrogen gas used in this study was of commercial purity with about $50 \mathrm{ppm}$ of residual oxygen and $14 \mathrm{ppm}$ of water vapour (maximum values). Crack growth behaviour in such a nitrogen gas with traces of oxygen and water vapour has been reported to be similar to that in air [14].

\section{(E) Effect of sequence of intermittent overstressing}

On the effect of sequence of overstress on fatigue crack growth retardation, it was shown that a compression-tension type of overstress provides a greater retardation than a tension-compression type overstress [13]. In order to see whether or not the sequence effect also appears on acceleration behaviour under intermittent overstressing, a few tests were conducted under compression-tension overstresses [Fig. 3(b)] in a nitrogen atmosphere, since all of the tests presented so far were run under tension-compression type overstresses. The results are shown in Fig. 8. The data points for compression-tension type overstresses lie near those for tension-compression type overstresses and an appreciable effect of sequence is not recognized. 

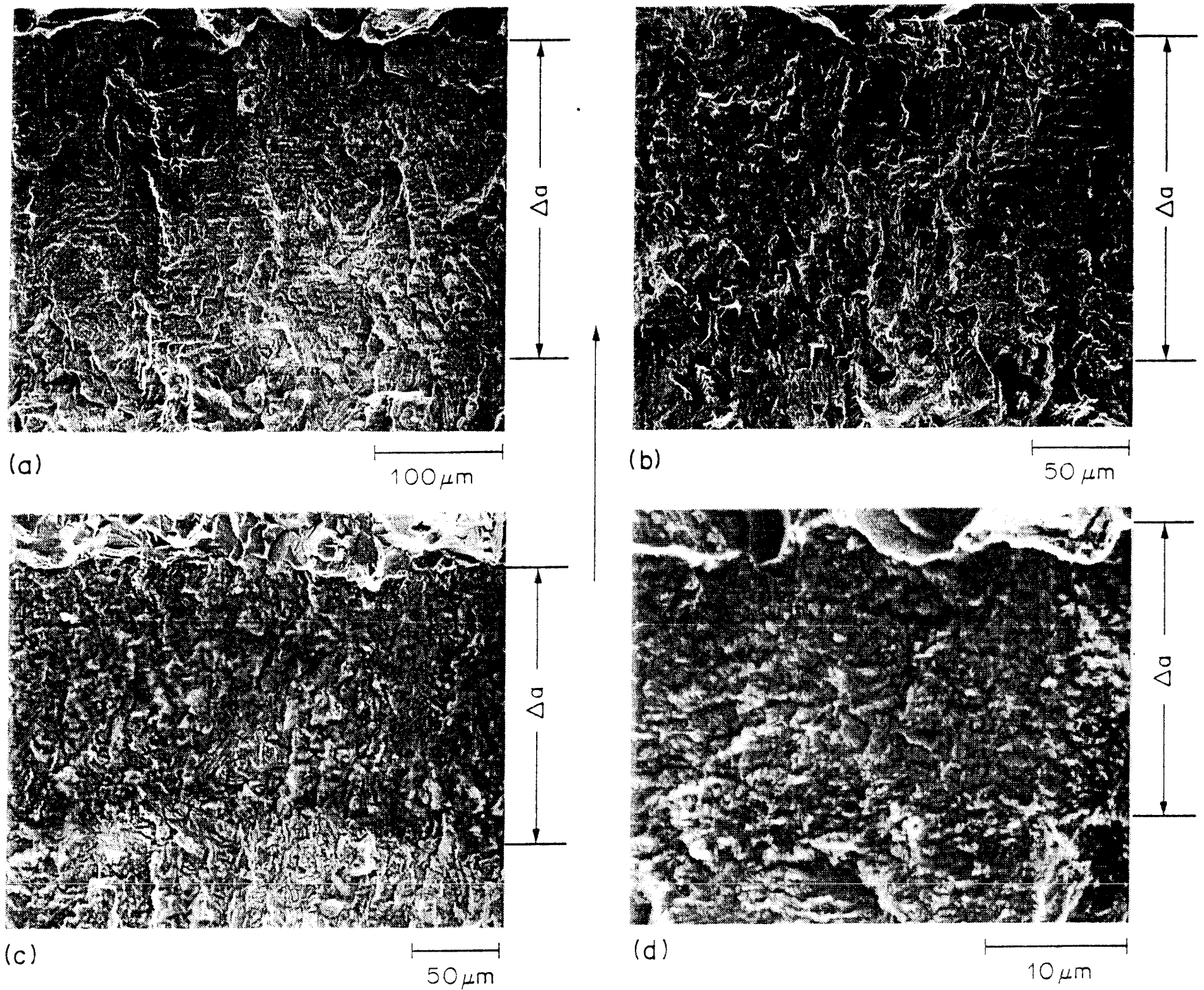

Fig. 7. Electron fractographs for fractures under intermittent overstressing in different environments. (a) Dry air $\left(\Delta K_{1} / \Delta K_{\mathrm{th}}=0.62, R_{\mathrm{ac}}=50\right)$, (b) nitrogen $\left(\Delta K_{1} \Delta K_{\mathrm{th}}=0.86, R_{\mathrm{ac}}=79\right)$, (c) moist air $\left(\Delta K_{1} \Delta K_{\mathrm{th}}=0.93 . R_{\mathrm{ac}}=76\right)$ and (d) vacuum $\left(\Delta K_{\mathrm{t}} / \Delta K_{\mathrm{th}}=0.60 . R_{\mathrm{ac}}=6\right) . \Delta a=$ crack growth under intermittent overstressing. The arrow indicates direction of crack growth.

The reason for the small effect of sequence on acceleration behaviour is because the effect of sequence on retardation behaviour is related to differences in crack closure behaviour associated with the different sequence of overstresses [13] while the acceleration of crack growth effect observed here is not caused by crack closure but by the recovery of the dislocation structure due to a large number of understress cycles as described earlier and hence would not be sensitive to the sequence of overstresses [2].

Table 1. Measured and estimated values of oxide thickness $\left(S_{0 x}=\right.$ measured. $S_{0 x}^{*}=$ estimated $)$

\begin{tabular}{lccccccc}
\hline \multirow{2}{*}{ Environment } & $\Delta K_{1} \Delta K_{\mathrm{th}}$ & $R_{\mathrm{ac}}$ & $\Delta K_{1}$ & $(\mathrm{M} \mathrm{Pa} \sqrt{\mathrm{m}})$ & $\Delta K_{\text {leff }}$ & $S_{\text {ox }}^{*}(\AA)$ & $S_{\mathrm{ox}}$ \\
\hline \multirow{3}{*}{ Moist air } & 0.93 & 76 & 5.8 & 2.0 & 3.8 & 1600 & 1700 \\
\multirow{2}{*}{ Nitrogen } & 0.73 & 54 & 4.6 & 2.6 & 2.0 & 1400 & 650 \\
\hline
\end{tabular}




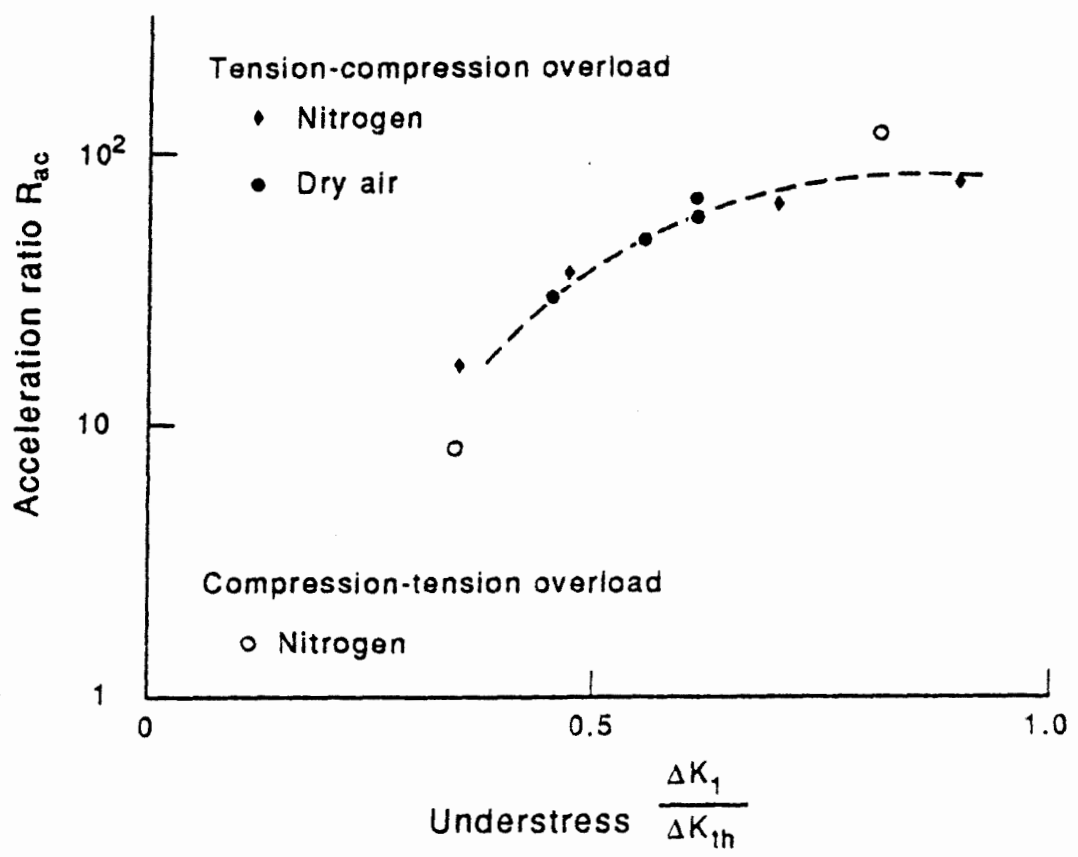

Fig. 8. Acceleration ratios for intermittent overstresses with different sequences of overstressing (tension-compression and compression-tension).

\section{CONCLUSIONS}

Fatigue crack growth tests under intermittent overstressing were carried out in moist air, dry air, nitrogen and vacuum with centre notched plate specimens of low carbon steels under tension-compression loading. The results are summarized as follows:

(1) A very small number of cycles of overstress applied intermittently during a very large number of cycles of understress (i.e. below threshold) caused a significant acceleration of crack growth in moist air, dry air and nitrogen. This is thought to be caused by a recovery of the dislocation structure due to the large number of understress cycles.

(2) In the phase of low understress, the acceleration in moist air was appreciably less than that in dry air and nitrogen. An analysis of fracture surfaces by Auger spectroscopy showed that an oxide film within cracks enhanced crack closure and caused the lower acceleration of crack growth in moist air.

(3) The acceleration in vacuum was smaller than that in other environments over all understress levels. Fractographic study suggested rewelding in vacuum as a possible cause for this case.

(4) There was no effect of overstress sequence on the acceleration, that is, a compressiontension type overstress gave about the same acceleration as a tension-compression type overstress.

Acknowledgement - The authors wish to express their cordial appreciation to colleagues at the University of Tsukuba for their assistance in conducting experiments.

\section{REFERENCES}

1. R. Koterazawa (1981) Fatigue crack propagation under periodic overstressing. In Proc. Fatigue '81, "Materials Experimentation and Design in Fatigue", Society of Environmental Engineers, Warwick, pp. 159-169. 
2. K. Katagiri, R. Koterazawa, T. Yamada and T. Tsuboi (1983) Changes in dislocation structures adjacent to fatigue crack tips induced by intermittent overstressing. Metal Sci. 17, 556-562.

3. R. Koterazawa (1986) Acceleration of fatigue and creep crack propagation under variable stresses. In Proc. Int. Conf. on Fatigue, Corrosion Cracking, Fracture Mechanics and Failure Analysis, "Fatigue Life: Analysis and Prediction", ASM, Salt Lake City, pp. 187-196.

4. For example, R. P. Wei and R. I. Stephens (1976) Fatigue crack growth under spectrum loads. ASTM STP 595.

5. W. A. Spitzig and R. P. Wei (1970) Fatigue-crack propagation in modified 300-grade maraging steel. Engng Fract. Mech. 1, 719-726.

6. A. Bignonnet, R. Namdar-Irani and M. Truchon (1982) The influence of test frequency of fatigue crack growth in air, and crack surface oxide formation. Scr. Metall. 16, 795-798.

7. D. L. Davidson and J. Lankford (1983) The effect of water vapor on fatigue crack tip mechanics in 7075-T651 aluminum alloy. Fatigue Engng Mater. Struct. 6, 241-256.

8. K. Komai, H. Matoba and J. Kikuchi (1984) Fatigue crack growth and closure behaviors of high-tensile strength steel in vacuum. J. Mater. Sci. Jap. 33, 566-571.

9. R. M. N. Pelloux (1969) Mechanism of formation of ductile fatigue striations. Trans. ASM 62, 281-285.

10. S. Suresh, G. F. Zamiski and R. O. Ritchie (1981) Oxide-induced crack closure: an explanation for near-threshold corrosion fatigue crack growth behavior. Metall. Trans. 12A, 1435-1443.

11. W. Elber (1971) The significance of fatigue crack closure, ASTM STP 486, pp. 230-242.

12. J. Schijve (1962) Fatigue crack propagation in light alloy sheet material and structures. In Advances in Aereonautical Sciences, Vols 3-4, pp. 387-408. Pergamon Press, Oxford.

13. R. I. Stephens, D. K. Chen and B. W. Hom (1976) Fatigue crack growth with negative stress ratio following single overloads in 2024-T3 and 7075-T6 aluminum alloys, ASTM STP 595, pp. $27-40$.

14. N. Ranganathan, B. Bouchet and J. Petit (1987) Fractographic aspects of the effect of environment on the fatigue crack propagation mechanism in a high-strength aluminum alloy, ASTM STP 948, pp. 424-446. 